\title{
The census as an information source in public policy-making
}

Journal of Information Science $1-10$ (C) The Author(s) 2015 Reprints and permissions: sagepub.co.uk/journalsPermissions.nav DOI: $10.1177 / 0165551510000000$ jis.sagepub.com

@SAGE

\section{Lynn Killick}

School of Computing, Edinburgh Napier University, UK

\section{Hazel Hall}

School of Computing, Edinburgh Napier University, UK

\author{
Alistair S Duff \\ School of Arts and Creative Industries, Edinburgh Napier University, UK
}

\section{Mark Deakin}

School of Engineering and the Built Environment, Edinburgh Napier University, UK

\begin{abstract}
This paper provides an assessment of the value of national population censuses as information sources with specific reference to UK census data and its use in policy-making. Mixed methods were adopted to collect quantitative and qualitative data from two sources: (I) a content analysis of policy documents, and (2) interviews with policy-makers in Scotland. The findings highlight that although the general value of the census is recognised, policy-makers are not necessarily closely engaged with the census as a tool for directing the development and implementation of policy. This is evident, for example in a lack of awareness of proposed changes to the census, and infrequent deployment of available data. The opportunity to change perceptions among policy-makers, and to expand the application of census data in public policy, is identified. With a novel focus on the deployment of censuses as sources of evidence for policy-making that includes the views of policy-makers from both within and beyond government, this work contributes to an established body of global research on international censuses.
\end{abstract}

\section{Keywords}

census; evidence-based policy; population census; public policy; Scotland; social policy; United Kingdom; UK

\section{Introduction}

The design and implementation of population censuses is currently subject to scrutiny across the globe. From the perspective of governments, the potential for cost savings, availability of new technologies, and increasing demand for reliable up-to-date information, have created the conditions for change [1] [2] [3] [4]. For example, on the basis of evidence gathered by a variety of means, including public consultation, it is proposed that the next census scheduled for 2021 in Scotland will involve online completion of returns. In addition, a complex data-sharing protocol is under development to allow for the combination of administrative records with this census data, so as to produce timely, and accurate, outputs. Such changes raise questions about informed consent for the sharing of data, as well as concerns about data security. In addition, some commentators suggest that levels of participation in a census may be affected by a move to online completion. This has been discussed widely, for example from a UK perspective [5]), and with reference to developments in New Zealand and Japan [6]). Given such interest in population censuses at this time, it is appropriate to consider their value as information sources.

The study reported here is concerned with the current value of UK census data as a source of evidence for deployment by policy-makers. Following an exposition of the study's main theme in a short literature review, the paper provides an account of how a mixed-methods approach, which includes the collection of both quantitative and qualitative data derived from content analysis of policy documents and interviews with policy-makers in Scotland, has led to a new and original set of perspectives on the UK census as an information source. The findings from this study identify an opportunity to raise the awareness of policy-makers of population censuses as information sources, and thus 
encourage and expand their application in public policy. They contribute to a body of international research on census data, with a novel focus on evidence for policy-making: the inclusion of policy-makers from beyond government as participants in this process adds a perspective to the work that is often missing from this type of research. The findings also highlight priorities for future research, notably consideration of the information skills required for the extraction of value from census data and its application in a policy-making context.

\section{Literature review}

\section{I. Main themes in the literature on population censuses}

The literature on population censuses pays attention to an extensive range of topics. These include, for example: the history of censuses and their place in society [7] [8] [9] [10] [11]; the use and misuse of census data [12] [13]; the ethics of population counts [14]; and the statistical validity of the varying methods for assessing population size [4] [15] [16] [17]. The relationship of census data to policy [18] [19] [20] [21] [22], as well as the information skills required for developing, implementing, and assessing it [23] [24] [25] [26] [27] [28] [29], are also covered in this body of published work. There are, however, few published research studies that refer specifically to censuses as sources of evidence for policy-making. This theme is the focus of the empirical research presented in this paper, as discussed in further detail below.

\subsection{Censuses as national data sets}

Despite concerns regarding the accuracy of traditional enumeration (see, for example, [2]), and variations in format [15], a nation's census is the primary source for its population statistics, and the source against which all others are compared. The benchmarking role of a nation's census, and its prominence as the core or basic national data set, is referred to explicitly in a number of studies (for example, [2] [30] [31] [32]). For example, a review of approaches to population counts notes that despite the diversity of approaches used "all the international efforts have something in common; they remain the indispensable benchmark of the national statistical system" [15].

A wide variety of data users are drawn to population censuses on account of their perceived reliability. Some access the data as it becomes available: in this case it is the data per se that represent the main data source [30]. Others refer to census outputs as reference points [31] [32]. Here census data inform the validation and interpretation of data derived from elsewhere. In addition, due to the longitudinal nature of censuses, the published data can be deployed to measure the impact of policy decisions [15]. These also allow for the general population "to validate quantifiable claims made by the government" [14]. Indeed, it has been noted that the absence of census data makes public scrutiny of policy decisions challenging [33] [34].

The unique role of population censuses in generating small area data is considered in discussions of their value (for example, [8] [15]). The term "small area data" is used internationally to refer to respondent demographics such as ethnicity, religion, age profile, and gender within a small geographic area, or to a small sub-population - such as a specific age, sex or race group - within a larger one. The size of population measured may be as small as 300 as designated by postcode. For specific characteristics, such as ethnicity, the area selected may be larger, such as electoral ward. This is to ensure respondent anonymity. No other source provides as reliable and detailed a data set across all fields, nor one that can be explored from the local (postcode) to national level. Small area data are regarded as essential to the identification of inequality and/or deprivation in society, and of social issues that require public policy intervention (for example, [35] [36] [37]). Despite the reported value of the small area data, however, recent proposals for changes to census counts that would result in their loss have been forwarded in a number of jurisdictions. For example, census data users in Canada objected to the replacement of traditional enumeration with a voluntary population survey on the grounds that this led to a loss of small area data. The Canadian Nurses Association, for instance, highlighted how the absence of small area data had a negative impact on activities such as pandemic and workforce planning, as well as signalled the loss of important data that could be used to verify those derived from other sources [14]. Likewise, Cohen and Hébert [33] criticised the Canadian decision on the basis that the loss of small area data would have a detrimental impact on public health policy. They also argued that such a change indicated a lack of interest on the part of the Canadian government in accountability for its own decisions. Similarly in the UK, proposed changes to the census that would have resulted in the loss of small area data formed part of a recent consultation entitled Beyond 2011 [38]. This sought to explore the future provision of population and socio-demographic statistics in Scotland. Responses to Beyond 2011 highlighted the negative implications of any such changes [39]. In this case demands from users for the continued publication of small area data far outweighed privacy or security concerns associated with capturing detailed data from Scotland's citizens. As a result the collection of small area data in Scotland will continue for the $2021 \mathrm{UK}$ census. 


\subsection{Census data in public policy-making}

As is the case in other nations, the UK government uses its national census as an information source for decisions on the distribution of resources to the regions according to population need [2] [17] [32]. This primary purpose of the UK census - to inform policy decisions that support the delivery of services - is noted on the web pages of the UK census offices [40] [41]. Such deployment of these census data was made evident in the statistics gathered in the course of the Beyond 2011 consultation [38] (cited above). On the basis of 125 responses received as part of this consultation [38], it was established that: $66 \%$ of UK census users access the data for policy development; $62 \%$ do so for monitoring and evaluation; $50 \%$ for service planning; and $46 \%$ for resource allocation. These findings derive from an analysis of responses provided by representatives from local authorities, non-departmental government bodies, and individual government departments, $57 \%$ of whom have the power to change and/or implement public policy. Other respondents included representatives from third sector organisations $(15 \%)$, higher education and the wider research community $(6 \%)$. The remaining $22 \%$ were others who responded on behalf of commercial bodies or privately, and those who did not specify their status.

This use of UK census data fits with an ideal that the delivery of public policy should be based on evidence. Commitments to this can be found in a wide range of sources, from white papers published by UK government departments to those of other political bodies such as the European Union and the United Nations [42]. Sitting governments and citizens have held such expectations for some time. For example, in 1999 the UK Labour government stated its ambition as one where "[The] government expects more of policy-makers. More new ideas, more willingness to question inherited ways of doing things, better use of evidence and research in policy making and better focus on policies that will deliver long term goals" [43]. The scale of the evidence required, and the reach of public policy, is wide. As Kauhanen-Simanainen [44, p.140] notes, the task of government is one "of solving international, regional and local problems, while planning ahead and predicting the possible effects of decisions, which have and will be taken... [including] the effective and efficient organisation of health, education, social and infrastructural services for the citizens", and that to achieve this a "solid, current, regularly updated knowledge base", which provides access to the latest information from as a wide a range of sources as possible is required.

However, much published material concerned with evidence-based policy, including a number of papers commissioned by government departments, concludes that the current use of evidence in policy-making does not meet ideals such as those set out by the UK Labour government in 1999. For example, Yeo [44, p. 314] notes that although evidence may be available, it does not necessarily mean that evidence-based policy follows. This aligns with views that access to information does not necessarily lead to an informed state of being (for example, [45, p. 32], [46]). Likewise, knowledge has been described as a "capacity for action", with the caveat that an option may be not to act on the knowledge available [47, p. 24]. That evidence can be actively ignored by policy-makers reflects the complexities of policy-making in general, and the political environment of public policy-making in particular [21, p. 700].

Various explanations have been advanced to explain why appropriate evidence is not systematically used in policymaking. Many relate to how information sources are accessed and the nature of the evidence assembled from such sources [23] [42] [44] [47] [48] [49]. For example, prior work has identified an over-reliance on lobbyists and external advisors for the delivery of digested data at the expense of using more reliable formal information sources such as those offered by government library services [23] [42] [48]. Other work has pointed to a reluctance or inability to act on the information that is readily available [47].

While it is possible here to identify studies that discuss evidence-based policy making and the role of information sources in informing this, the contribution of the UK population census in determining public policy-making has, to date, not been explored. The question of the extent to which policy-makers are aware of, value, and deploy UK census data in policy-making motivated the empirical work discussed below. The means of addressing this question are addressed first.

\section{Research design: site selection, data collection and data analysis}

\section{I. Overview of the research design}

The work reported here contributes to a larger study that explores the future role of the UK population census, and its role in informing the good society. This element of the larger piece of work considers census data as a source of evidence for deployment by policy-makers. The findings discussed here derive from (1) a content analysis of twenty policy documents published by the Scottish Government in 2015, and (2) twenty semi-structured interviews with individuals who have responsibility for developing, delivering or assessing the implementation of public policy in Scotland. The first exercise involved the collection and analysis of quantitative data. The findings of this analysis subsequently informed the development of a semi-structured interview framework that was deployed to gather largely 
qualitative data from the policy-makers. The data collection was carried out over a period of eight months from January 2015 (when the first policy document was downloaded) to September 2015 (when the last interview took place).

\subsection{Content analysis of Equality Impact Assessments (EQIAs)}

The documents examined in the first stage of the research were Equality Impact Assessments (EQIAs). All public bodies in Scotland, including the Scottish Government, publish EQIAs to demonstrate that consideration has been given to the equality implications of any policy during its formation process. EQIAs include details of the evidence analysed as part of the process of assessing the potential impact of applying a proposed new or revised policy or practice. It is a legal requirement for EQIAs to be published, as per the terms of The Equality Act 2010 (Specific Duties) (Scotland) Regulations 2012 [50]. Under the heading "Duty to assess and review policies and practices" this states that:

- "A listed authority must, where and to the extent necessary to fulfil the equality duty, assess the impact of applying a proposed new or revised policy or practice."

- "In making the assessment, a listed authority must consider relevant evidence relating to persons who share a relevant protected characteristic."

- “A listed authority must publish, within a reasonable period, the results of any assessment made."

This legal compulsion on listed authorities to furnish evidence of their decision-making aligns with the House of Commons Science and Technology Committee's call for transparency in the use of evidence in policy-making. Of particular note is the recommendation that it should be made clear where decisions are made without reference to evidence [51].

The Scottish Government published all the EQIAs selected for this study in 2015. They represent documents prepared in the 12 months from the release of the first results of the 2011 UK census. They were selected for review primarily on the basis that they derived from a trusted source. The content analysis set out to determine the following for each of the documents in the set:

(1) Mentions of 2011 UK census: general mention, and/or specific references to particular data sets

(2) Mentions of Scottish Household Survey This provides household and individual information to support the work of communities, local government and transport areas, and the work of the Scottish Parliament. The data are collected by interview from around 3,900 households on a quarterly basis. Much of the value of this survey is that the results allow for early detection of trends. This is less achievable for other statistical sources that are published less frequently and with significant time-lags between data collection and public availability of results, as is the case with the UK census (the results of which are released in phases from the year following data collection).

(3) Mentions of any third party research

(4) Justifications for the absence of evidence

The topic of each publication was also recorded according to Scottish Government directorate, for example health, justice, education. Nvivo ${ }^{\mathrm{TM}}$ was used to implement the coding scheme developed for the content analysis. Given that the focus of this paper is the UK census, findings related to item 1 above are detailed below. (Findings on the other elements will be disseminated in due course.)

\subsection{Interviews with policy-makers}

The design of the interview schedule deployed in the second data collection exercise was determined by the findings of both the evaluation of relevant literature and the output of the content analysis. The primary purpose of conducting the interviews was to elicit data that would allow for an exploration of how policy-makers use census data (amongst other sources) in their work on policy formation and governance.

Following piloting of the interview schedule in March 2015, twenty interviews were conducted over a five-month period between May and September 2015. The profile of the sample selected for interview is shown in Table 1. The first set of interviewees is classified under the label "internal" to government. This is on the basis that these ten interviewees all set, or implement, government policy. They work across a range of areas including community planning, education, enterprise, health, housing, and justice. Three members of this group are noted as "non-executive directors". These are board members of public bodies who work alongside the bodies' directors in policy-making and planning exercises. The non-executive role, however, does not include day-to-day management of the body with which it is associated. Members of the second set, labelled here as "external", either work to influence the policy direction of the sitting government, and/or hold the government to account. The professional interests of members of this group include disability equality, 
housing, race relations, and social care. The inclusion of the set of external participants adds to the novelty of this research. Normally work of this nature is narrowly focused on those policy-makers who work within government only, and thus fails to recognise the contributions to policy development and assessment by external third parties.

Table I. Interviewee profiles

\begin{tabular}{llr}
\hline Interviewee relationship to government & Number of interviewees \\
\hline Internal & Employer & 4 \\
& Scottish Government \& Public Bodies (civil servants) & 3 \\
& Scottish Government \& Public Bodies (non-execs) & 3 (2 current, I former) \\
& Local authority & 5 \\
External & Third sector organisation & 5 \\
& Regulatory body & 20 \\
\hline
\end{tabular}

The interviews lasted between 30 and 80 minutes, with an average length of 40 minutes. The interviews were recorded and transcribed, then coded using the same software deployed for the content analysis $\left(\mathrm{Nvivo}^{\mathrm{TM}}\right)$. The analysis of the data collected by interview set out to determine how the interviewees perceive the UK census as an information source with a focus on the value that they assign to it, and how census data are deployed in practice for the purposes of policy-making. Attention was also paid to levels of awareness of the Beyond 2011 [38] consultation on the proposed changes to the UK census.

\section{Findings}

\section{I. Evidence of the use of census data in policy documents (content analysis)}

Just five of the twenty Scottish Government-published EQIAs selected as the sample for this study noted the census as a source of evidence. In four of these cases the citations simply comprised general high-level references to "the census" without mention of its year of publication, or to any particular data set. From the evidence identified in these four cases there is little confidence that those responsible for the publication of the EQIAs had examined census data in depth beyond the national headline figures. In the single case where census data had been used as part of the analysis, the data presented related to a single population group (the disabled). Of note here is that this EQIA was the output of a partnership between a government department and an equality expert whose role was to work with an arm's length body with responsibility for discharging the government's function. This provides an example of the benefits of the type of collaborative working advocated by Kauhanen-Simanainen in 2007, as noted above [44].

The use of the census as a source of evidence for the EQIAs was not as extensive as had been anticipated. However, it should be recognised that it is unlikely that every EQIA would be informed by census data from 2011, and not every policy area can benefit from such a source. For example one EQIA in the sample was concerned with human trafficking. This made specific reference to the absence of evidence, noting that by its nature this policy area was a topic unlikely to benefit from the use of UK official statistics.

\subsection{Awareness of the census as an information source}

Although there is limited evidence of the use of UK census data in the policy documents selected for review in this study, the majority of interviewees believe it appropriate for national policies, or policy directions, to consider detailed census results where applicable, as can be seen in Table 2.

Table 2. Is it appropriate that detailed census data be referenced in national policy decisions?

\begin{tabular}{lrr}
\hline Interviewee relationship to government & Yes & No \\
\hline Internal & 5 & 5 \\
External & 10 & 0 \\
Total & 15 & 5 \\
\hline
\end{tabular}


Perhaps more telling than the data summarised above, however, is the level of awareness of the Beyond 2011 consultation [38] on the future of the UK census. This was low amongst the interviewees, as shown in Table 3 . Here it can be seen that the majority were completely unaware of the consultation (12). Two thirds of these study participants (8) are internal to government. The interviewees who were unaware of Beyond 2011 [38] were surprised to learn about the extent to which the census might have changed or be changing. Of the remaining eight, all of whom had some level of awareness of the consultation, four had contributed to responses to the proposals with support for the maintenance of the census. Three of the four had also attended a census consultation outreach event.

Table 3. Awareness of the Beyond 20I I consultation

\begin{tabular}{lrr}
\hline Interviewee relationship to government & Aware & Unaware \\
\hline Internal & 2 & 8 \\
External & 6 & 4 \\
Total & 8 & 12 \\
\hline
\end{tabular}

As might be expected, those who were familiar with, and had engaged in the Beyond 2011 [38] consultation, were strong advocates for the census. For example, one interviewee favoured more frequent reporting, and three were keen that the provision of small area data continue, cautioning against cost-cutting exercises or alternative methods that would lead to estimations of population numbers, and in turn, estimations of population diversity. This question of value, and the different attitudes of the two types of policy-maker interviewees, is explored in greater detail below.

\subsection{Value assigned to the census and its application in policy-making}

It was clear from the interview data that, at a general level, the census is valued by policy-makers. Some comments made on the question of value were enthusiastic. For example, when referring to the census as a benchmarking tool (a primary function as noted in the literature [for example, 15]) one interviewee remarked: "Without it we couldn't demonstrate that we were doing our job... It's our only measure of progress". Others highlighted the benefits of being able to dig beneath the headline findings and access the anonymised raw data. These can then be segmented (for example by gender, ethnicity, disability or income levels) and further exploited "locally" for specific purposes. Recast in report format, these data can demonstrate successes and failures in the design and/or implementation of earlier policy, with the expectation that the future policy-making behaviours of the bodies in question may be positively influenced. Such evidence confirms the importance of small area data, as has been previously identified in the literature and noted above (for example, [8] [15]). This finding is also in line with commentary in the prior literature which argues that - due to its longitudinal nature - census data can be deployed to measure the impact of policy decisions [15].

However, it should be noted that such applications of census data, which are largely focused on benchmarking, are less about directing policy and relate more closely to the use of the census as a tool to hold government to account, as has been highlighted in prior research [8]. It is also significant that although there was the general support for the use of the census in policy-making amongst the interviewees, few admitted to using census data directly in their work. This can be seen in Table 4 below.

Table 4. Access to census data

\begin{tabular}{lr}
\hline Census data accessed & Number of interviewees \\
\hline Direct access to detailed findings & 3 \\
Direct access to top level reports & 5 \\
Indirect access through third party analysis & 9 \\
None & 3 \\
Total & 20 \\
\hline
\end{tabular}

Of particular interest here are the different practices of the internal and external interviewees. The externals demonstrated that they were most keen to work with census data. They explained, for example, how they collaborate with statisticians to generate factual evidence that can be presented to a range of bodies, including the Scottish Government. In contrast, those who work internal to government are less likely to value census data as a tool to inform policy. Indeed half the internals reported that they do not consider it appropriate that census data be used as a tool in policy-making. Even those externals who do see value in the value of the census as an information source demonstrated lower levels of engagement. For example, a civil servant stated that since nobody had ever requested census data more detailed than that already provided, it followed that the level of provision to date must be appropriate. 
Those who actively use and value the census are mostly either closely involved in supporting specific groups (they work for the regulatory bodies or for the third sector) or support service delivery at local level (they work for local authorities). An explanation for this level of support from these two groups of externals is evident from comments made by the internals who argued that census data, particularly those related to local areas, are more relevant as aids to the local implementation of policy, rather than its development at national level. One view was that while census data could be used to address issues pertinent to specific segments of the population - for example in efforts to address inequalities - this evidence source is less relevant to policy-making as related to the population as a whole. Such remarks add to the evidence of the high regard for small area data.

While the internals explained why the externals regard the census more favourably, the externals reflected on why the internals were less enthusiastic about its use as an information source. For example, one surmised that those internal to government may not wish to explore issues in more depth, and/or in the light of specific data sets, as this may illuminate past failings. The same person added that it was difficult for well-meaning employees, who believed they were doing good work, to contemplate that their output could be improved (for example, through better analysis of information), especially in cases where organisational culture does not encourage innovation or is risk-averse.

A number of other explanations for low use of the census as an information source were suggested by the interviewees. These relate to the quality of the data per se (including its timeliness, accuracy and completeness), and the influence of external factors such as the availability of alternative information sources (including lobbying) and information skills. Significantly the majority (18) commented on the ease with which census data can be dismissed on the grounds that they are out-of-date. There was understanding of why census data take so long to produce: one interviewee referred explicitly to the relationship between the speed of publication of reports and the quality of data sets, inferring that if data are to have long-term value and not become obsolete quickly, then time needs to be invested in their generation. However, appreciation of this may not be widespread. Thus the policy-makers interviewed for this study remarked that it is difficult to argue the case for evidence that emerges from the census as a tool of influence when the census itself can be so easily dismissed. They also identified the need for robust lines of defence, particularly if census data from 2011 are to be applied in the period up until 2021 and beyond. In addition the interviewees highlighted deficiencies in self-reported census data, for example that related to caring responsibilities (which are often underreported) or perceived ill-health. The need to critically engage with the census as one of a number of evidence sources was also a concern: census data alone are insufficient for policy-making purposes, and for this reason the results of other population surveys need to be consulted alongside them. This finding relates to the use of census data as reference points as has been identified above with reference to commentary in previously published studies [31] [32].

As well as the questions of relevance and accuracy of census data, some interviewees also made reference to the political environment in which internal policy-makers work. They inferred that the content of the census, and its availability, are not the major factors that determine whether or not it is used. Rather, political imperatives and organisational pressures are more likely determinants of policy development. The externals who have used census data to highlight deficiencies in existing policy, or as an influencing tool, exhibited frustration at the apparent reluctance of internal policy-makers to engage with this information source. They considered the interest of senior civil servants and politicians in census data to be fleeting and superficial. Instead of using census data in a systematic way to support decisions to effect change for the good of all, these externals claimed that policy-makers are more often seen to take action on a case-by-case basis, reacting when third parties highlight issues that demand attention. This finding is in line with earlier work that draws attention to the power of lobbying, as discussed above.

Explanations for low use of the census as an information source may also be tied to the level of skills of policymakers in accessing, acquiring, analysing, and applying relevant information to their work, as has been noted elsewhere [23] [48]. Just three of the interviewees included in this research had received any specialist training in the use of census data. Indeed this study revealed evident reluctance on both the part of the majority of interviewees, and others with whom they work, to use census data directly. As one interviewee explained, "It's just too complicated". The interviewees also referred to possible misuse of census data by those untrained in its application: "In the wrong hands [the census] is dangerous, and there are a lot of wrong hands".

\section{Discussion and conclusions}

The findings of this research contribute to an established body of research on population censuses. Aspects of the role of the census as an information source that can be used for policy-making have been determined through a content analysis of twenty policy documents, combined with findings derived from twenty interviews with policy-makers from both within and beyond government.

It has been shown that despite the dominant view that the census is valuable, policy-makers are not necessarily closely engaged with the census for directing the development and implementation of policy. Those who contributed to the study provided a number of explanations for this. An external (who admitted that he was a "light" user of census data himself) drew attention to the core problem here: the census is a fundamental societal asset, albeit one that is not 
exploited as it should be. It thus does not meet the aspiration of its official stated purpose of supporting the delivery of public services [41].

That the interviewees spoke of the potential for positive change in cases where census data are interpreted and applied appropriately at national level implies an opportunity to raise the awareness of the census as a data source amongst policy-makers, and to expand its application in public policy. The low levels of awareness of possible major changes to the UK census (as articulated, for example, in the Beyond 2011 [38] consultation) further illustrates a lack of familiarity with the workings of the census, particularly among government insiders. The work presented here suggests that greater engagement with the census is necessary to support the UK's long-stated ambitions for evidence-based policy-making.

A key, and original, contribution of this study is the distinction between policy-makers who are internal and external to government. Here it has been demonstrated that those who contribute to policy-making and assessment in external bodies are more closely engaged with the census, and particularly with small area data. They are also more positive in their attitudes to the census as an aid to policy-making than their counterparts within government. This reinforces the proposition that the value of information, in this case that derived from the census, will increase in line with the frequency of its use [32, p.133]. The methodological decision to include policy-makers from beyond government as participants in the present study has made it possible for this finding to come to the fore.

While not a focus of this paper, this work also confirms indications from earlier research that well-developed information skills are required in those who wish to effectively extract value from information sources for application in a policy-making context (for example [23] [44]). This aspect of the work merits further exploration with reference to the theme of information literacy, particularly as previously examined in the public sector (for example, [52] [53]) and as related to the workplace (for example, [54]). Such future work should take into account prior research and the range of existing frameworks that this has generated (for example [55]).

A further analysis of EQIAs is planned to establish whether the availability of more current UK census data will impact on the level of detail contained within policy documents. If it is found that the policy documents do not include further detail or explanations regarding the level of data accessed, then it would be worth conducting a wider study to assess whether this is a reflection of the policy-making process or this simply reflects the time-lag from collection of the census (2011) to the release of the full data set (2015) (as noted in section 3.2 above). What seems clear, above all, is that the population census, however construed, merits further consideration as a vital source of information for the development of the good society.

\section{Acknowledgements}

The authors of this paper would like to thank the interviewees for their time and frank contributions, without which this research would not have been possible. They are also grateful to two anonymous referees whose helpful comments and suggestions contributed to the preparation of the final version of this paper for publication.

\section{Funding}

This work was supported by the Arts and Humanities Research Council [grant number AH/K002899/1].

\section{References}

[1] Boyle P, Dorling D. The 2001 UK census: remarkable resource or bygone legacy of the "pencil and paper era"? Area, $2004 ; 36$ 101-110

[2] Coleman D, The twilight of the census. Population Development Review, 2013; 8 334-351

[3] Dugmore K, Furness P, Leventhal B, Moy C. Beyond the 2011 census in the United Kingdom: with an international perspective. International Journal of Market Research, 2011; 619-650

[4] White I. The 2011 Census taking shape: methodological and technological developments. Population Trends, 2009 ; 135 64-72

[5] Cullen R. Culture, identity and information privacy in the age of digital government. Online Information Review, $2009 ; 33$ 405-421

[6] Heeney C. Breaching the contract? Privacy and the UK Census. The Information Society, 2012; 28(5) 316-328

[7] Christopher AJ. The quest for a census of the British Empire C.1840-1940. The Journal of Historical Geography, 2008; 34(2) 268-285

[8] Dale, A. Developments in census taking in the last 25 years. Population Trends, 200(100) 40-46

[9] Johansen HC. Early Danish census taking. The History of the Family, 2004; 9(1) 23-31

[10] Pearce AJ. The Peruvian population census of 1725-1740. Latin American Research Review, 2001; 36 69-104

[11] Shoemaker N. The census as civilizer. historical methods: A Journal of Quantitative and Interdisciplinary History, 1992; 4-11

[12] Aly G, Roth KH. The Nazi census: identification and control in the Third Reich. 2004 Philadelphia: Temple University Press

[13] Christopher AJ. Delineating the nation: South African censuses 1865-2007. Political Geography, 2009; 28(2) 101-109

[14] Deonandan RS. The mandatory census: tension between individual rights and the public good. Canadian Journal of Public Health. 2011; 102(6) 414-416 
[15] Baffour B, King T, Valente P. The modern census: evolution, examples and evaluation. International Statistical Review. 2013; 81(3) 407-425

[16] Diamond I, Abbott O, Jackson N. Key issues in the quality assurance of the one number census. Population Trends. 2003; 11-9

[17] Simpson S, Dorling D. Those missing millions: implications for social statistics of non-response to the 1991 Census. Journal of Social Policy. 1994; 23(4) 543-567

[18] Boaz A, Grayson L, Levitt R, Solesbury W. Does evidence-based policy work? Learning from the UK experience. Evidence and Policy: A Journal of Research, Debate and Practice. 2008; 4 233-253

[19] Pawson R, Wong G, Owen L. Known knowns, known unknowns, unknown unknowns: the predicament of evidence-based policy. American Journal of Evaluation. 2011; 32(4) 518-546

[20] Sanderson I. Is it "what works" that matters? Evaluation and evidence-based policy-making. Research Papers in Education. 2003; 18 331-345

[21] Sanderson I. Intelligent policy making for a complex world: pragmatism, evidence and learning. Political Studies. 2009; 457(4) 699-719

[22] Wastell DG. Information systems and evidence-based policy in multi-agency networks: the micro-politics of situated innovation. Journal of Strategic Information Systems. 2006; 15(3) 197-217

[23] Foreman J, Thomson L. Government Information Literacy in the "century of information". Journal of Information Literacy. 2009; 3(2) 64-72

[24] Greyson DL, Cunningham C, Morgan S. Information behaviour of Canadian pharmaceutical policy makers. Health Information and Libraries Journal. 2012; 29(1) 16-27

[25] Karunakaran A, Reddy MC, Spence PR. Toward a model of collaborative information behaviour in organisations. Journal of the Association for Information Science and Technology. 2013; 64(12) 2437-2451

[26] Lombard E. Pursuing information literacy. Oxford; Chandos, 2010

[27] Mutch A. Managing information and knowledge in organisations; a literacy approach. New York: Routledge; 2008

[28] Shah C. Collaborative information seeking: The art and science of making the whole greater than the sum of all. Berlin: Springer, 2012

[29] Xiao L, Easrmure V. Information use in group decision making teams. Proceedings of the American Society for Information Science and Technology. 2014; 51(1) 1-4

[30] Chertov O, Aleksandrove M. Using association rules for searching levers of influence in census data. Social and Behavioral Sciences 2013; 73 475-478

[31] Cook L. The quality and qualities of population statistics, and the place of the census. Area. 2004; 36(2) 111-123

[32] Feather, J. The information society: a study of continuity and change. $6^{\text {th }}$ ed. London: Facet, 2013.

[33] Cohen M, Hebert PC. Ideology trumps evidence with new voluntary survey. Canadian Medical Association Journal. 2010; $182(12)$ E541

[34] Dale A, Marsh C. The 1991 Census user's guide. London: HMSO

[35] Brown, M., \& Gardiner, C. Informing policy-making at sub-local authority spatial levels: using small area micro-data from the 2001 Census. Local Government Studies, 2004; 30(1) 74-87

[36] Giusti C, Marchetti S, Pratesi M, Salvati N. Robust small area estimation and oversampling in the estimation of poverty indicators. European Survey Research Association, 2012

[37] Tarozzi A, Deaton A. Using census and survey data to estimate poverty and inequality for small areas. Review of Economics and Statistics. 2009: 773-792

[38] Beyond 2011 Consultation http://www.gro-scotland.gov.uk/statistics-and-data/beyond-2011-the-future-of-censusstatistics/consultations-and-events/consultations/user-requirements (2013, accessed 30 September 2015)

[39] Summary of user requirements http://www.ons.gov.uk/ons/about-ons/get-involved/consultations-and-usersurveys/consultations/beyond-2011-consultation/beyond-2011-consultation-doc-c2.pdf (2013, accessed 30 September 2015)

[40] 2011 Census. Office for National Statistics http://www.ons.gov.uk/ons/guide-method/census/2011/index.html (accessed June 2015)

[41] Welcome to Scotland's Census http://www.scotlandscensus.gov.uk (2015, accessed 30 September 2015)

[42] Pawson R. Evidence-based policy: a realist perspective. London: Sage, 2006

[43] Modernising Government. London: HMSO, 1999

[44] Kauhanen-Simanainen A. Corporate literacy: discovering the senses of the organisation. Oxford: Chandos, 2007

[45] Yeo M. The rights of science and the rights of politics: lessons from the long-form census controversy. Canadian Journal of Sociology. 2012; 37(3) 295-315

[46] Webster F. Theories of the information society. $4^{\text {th }}$ ed. Abingdon: Routledge, 2014.

[47] Stehr, N. Knowledge politics. London: Paradigm, 2005

[48] Campbell, S, Benita, S, Coates, E. Davies, P. \& Penn, G. Analysis for policy: evidence-based policy in practice http://www.civilservice.gov.uk/wp-content/uploads/2011/09/Analysis-for-Policy-report_tcm6-4148.pdf (2007, accessed 30 September 2015)

[49] Panagiotopoulis P, Bowen F. Conceptualising the digital public in government crowdsourcing: social media and the imagined audience. In: Tambouris E, Janssen M, Scholl HJ, Wimmer MA, Tarabanis K, Gasco M, Kilevink, B, Lindgren, I \& Parycek, P. (Eds) Proceedings of 14th IFIP WG 8.5 International Conference, EGOV 2015, 19-30, 2015

[50] Equality Act 2010 http://www.legislation.gov.uk/ukpga/2010/15/contents (2010, accessed 30 September 2015)

[51] House of Commons Science \& Technology Committee http:/www.publications.parliament.uk/pa/cm200506/cmselect/cmsctech/cmsctech.htm (2006, accessed 30 September 2015) 
[52] Baxter, G, Marcella, R \& Illingworth, L. Organizational information behaviour in the public consultation process in Scotland. Information Research, 2010; 15(4) http://InformationR.net/ir/15-4/paper442.html (accessed 11 December 2015)

[53] Crawford, J. \& Irving, C. Information literacy in the workplace: a qualitative exploratory study. Journal of Librarianship and Information Science, 2009; 41(1), 29-38.

[54] Lloyd, A. Trapped between a rock and a hard place: what counts as information literacy in the workplace and how is it conceptualised? Library Trends, 2011, 60(2), 277-296.

[55] Crawford, J. \& Irving, C. Information literacy, the link between secondary and tertiary education project and its wider implications. Journal of Librarianship and Information Science, 2007; 39(1), 17-26. 